\title{
CLINICO-MICROBIOLOGICAL SPECTRUM OF INFECTIVE ENDOCARDITIS IN PATIENTS FROM A TERTIARY CARE IN CENTRAL INDIA
}

\section{Dr Mamta Meena}

\section{Dr Nitesh Arora*}

\section{Dr Raghvendra} Singh Meena
MD Microbiology, Assistant Professor, Department Of Microbiology, Gandhi Medical College, Bhopal

MD General Medicine, Senior resident, Department of Cardiology, Gandhi Medical College, Bhopal. *Corresponding Author infective endocarditis presenting in a tertiary care institute in India. MATERIALS AND METHODS: A retrospective study based on evaluation and systematic review of 118 patients admitted in department of cardiology, Gandhi Medical College, Bhopal of Definitely diagnosed infective endocarditis, based on modified dukes criteria(1). The demographic Details of patients such as age, sex, clinical findings, prior antibiotic usage were noted along with three sets of blood cultures were sent for microbiological profile. The specimens were processed using BACTec 9240 automated system. RESULTS : the mean age being 30 years, ranging between 20-70 years, with major of the age group being 41 50 years.(table 1) with male predominance (M:F 1.4:1). Most of the Patients presented with complain of fever(67.7\%,n=80), infective emboli $(17.7 \%, n=21)$. Majority of the patients had Native valve endocarditis $(83.05 \%, n=98)\{25.5 \%(n=25.5)$ culture positive Vs $74.4 \%(n=73)$ culture negative $\}$ and $16.9 \%(n=20)$ had prosthetic valve endocarditis $\{65 \%(n=13)$ were culture positive Vs $35 \%(n=7)$ culture negative $\}$ with most common underlying heart conditions being rheumatic heart disease $77.9 \%(n=92)$, prosthetic heart valve $16.9 \%(n=20)$, ASD $1.6 \%(n=2)$, VSD $3.3 \%(n=4)$. The most common valve involved as mitral valve $(50 \%, n=59)$ followed by aortic $(28 \%, n=23.7)$, tricuspid $(17.7 \% n=21)$ and lastly pulmonary valve $(8.4 \%, \mathrm{n}=10)$. The microbiological spectra noted in NVE culture positive cases the most common organism isolated were Streptococcus mitis $(36 \% n=9)$, Streptococcus sanguinis $(12 \%, n=3)$, Streptococcus pyogenes $(12 \% n=3)$. Whereas in PVE culture positive cases the most common organism isolated were Methicillin Resistant Staphylococcus aureus (MRSA) (30.7\%,n=4), Methicillin susceptible Staphylococcus aureus(MSSA) $(30.7 \%, \mathrm{n}=4)$, Methicillin Resistant Coagulase negative Staphylococcus (MRCONS) $(23.0, \mathrm{n}=3)$, Streptococcus pyogenes $(15.3 \% \mathrm{n}=2)$.

KEYWORDS : Infective Endocarditis, Microbiological Spectrum, Central India, Native Valve Endocarditis, Prosthetic Valve Endocarditis

\section{INTRODUCTION}

Infective endocarditis is one of the prevalent diseases in india which effects heart endothelium, which is quite prevalent in india and other developing countries due to high prevalance of Chronic Rheumatic Heart disease. Although the disease being very prevalent in our society only a few studies are available which highlight the microbiological spectrum of the of the disease in India, as compared to the west, where vast amount of data is available through various studies. This study highlights the clinic-microbiological parameters of patients with infective endocarditis presenting in a tertiary care institute in India.

\section{MATERIALS AND METHODS:}

The Study was a retrospective study based on evaluation and systematic review of 118 patients admitted in department of cardiology, Gandhi Medical College, Bhopal of Definitely diagnosed infective endocarditis, based on modified dukes criteria(1). The demographic Details of patients such as age, sex, clinical findings, prior antibiotic usage were noted along with three sets of blood cultures were sent for microbiological profile. The specimens were processed using BACTec 9240 automated system.Tissue cultures were incubated for 21 days, antibiotic susceptibility testing was performed by disc diffusion method or Minimal inhibitory concentration (MIC) methods as recommended by CLSI and British Society for Antimicrobial Chemotherapy (BSAC) protocols, whichever was applicable. MIC was performed using Vitek2 system or E-strips as recommended. Microbiological outcome was determined as type / frequency of microorganisms isolated, antimicrobial susceptibility pattern of those isolates. All negative cases were reported "no growth" after incubation of 21 days.

The Data analysis was done Using SPSS ver 20 using which Mean and standard deviation of the continuous variables as well as Frequency and percentage of the categorical variables gender were calculated.

\section{RESULTS:}

The Baseline characteristics:

A total of 118 patient records were reviewed and the age range of the patients was $11-80$ years, the mean age being 30 years, ranging between 20-70 years, with majority of the age group being 41-50 years.(table 1) with male predominance (M:F 1.4:1). Most of the Patients presented with complain of fever $(67.7 \%, \mathrm{n}=80)$, infective emboli $(17.7 \%, \mathrm{n}=21)$, asymptomatic heart murmur $(8.4 \%, \mathrm{n}=10) \&$ Chest discomfort $(5.9 \%, \mathrm{n}=7)$. Majority of the patients had Native valve endocarditis $(83.05 \%, \mathrm{n}=98)$, of which $25.5 \%(\mathrm{n}=25.5)$ were culture positive and $74.4 \%(\mathrm{n}=73)$ were culture negative. Whereas $16.9 \%(n=20)$ were prosthetic valve endocarditis of which $65 \%(n=13)$ were culture positive and $35 \%(n=7)$ were culture negative. Majority of the Patients with endocarditis were associated with underlying heart conditions the most common being rheumatic heart disease $77.9 \%(n=92)$, prosthetic heart valve $16.9 \%(n=20)$, ASD $1.6 \%(n=2)$, VSD $3.3 \%(n=4)$. The most common valve involved as mitral valve $(50 \%, \mathrm{n}=59)$ followed by aortic $(28 \%, \mathrm{n}=23.7)$, tricuspid $(17.7 \% \mathrm{n}=21)$ and lastly pulmonary valve $(8.4 \%, \mathrm{n}=10)$. The microbiological spectra noted in NVE culture positive cases the most common organism isolated were Streptococcus mitis $(36 \% n=9)$, Streptococcus sanguinis $(12 \%, n=3)$, Streptococcus pyogenes $(12 \% \mathrm{n}=3)$. Whereas in PVE culture positive cases the most common organism isolated were Methicillin Resistant Staphylococcus aureus (MRSA) $(30.7 \%, \mathrm{n}=4)$, Methicillin susceptible Staphylococcus aureus (MSSA) (30.7\%, $\mathrm{n}=4)$, Methicillin Resistant Coagulase negative Staphylococcus (MRCONS) $(23.0, n=3)$, Streptococcus pyogenes $(15.3 \% \mathrm{n}=2)$.

Table 1: Age Distribution of patients $(n=118)$

\begin{tabular}{|l|l|}
\hline Age(in years) & frequency \\
\hline $0-10$ & 0 \\
\hline $11-20$ & 2 \\
\hline $21-30$ & 9 \\
\hline $31-40$ & 30 \\
\hline $41-50$ & 42 \\
\hline $51-60$ & 25 \\
\hline $51-60$ & 10 \\
\hline $61-70$ & 0 \\
\hline More than 70 & 0 \\
\hline
\end{tabular}


Table 2: Clinical Presentation at the time of Diagnosis

\begin{tabular}{|l|l|l|}
\hline Clinical Presentation & Number of patients(n) & Percentage(\%) \\
\hline Fever & 80 & 67.7 \\
\hline Infected emboli & 21 & 17.7 \\
\hline Heart Murmur & 10 & 8.4 \\
\hline Chest Discomfort & 7 & 5.9 \\
\hline
\end{tabular}

Table 3: Distribution of Infective endocarditis according to type of Valve Involved

\begin{tabular}{|l|l|l|l|}
\hline Type & $\mathbf{N}(\%)$ & Culture Positive N(\%) & Culture Negative N(\%) \\
\hline NVE & $98(83.05)$ & $25(25.5)$ & $73(74.4)$ \\
\hline PVE & $20(16.9)$ & $13(65)$ & $7(35)$ \\
\hline
\end{tabular}

Table 4: Underlying Cardiac Conditions

\begin{tabular}{|l|l|l|}
\hline Cardiac Condition & Frequency(=n) & Percentage (\%) \\
\hline Rheumatic Heart Disease & 92 & 77.9 \\
\hline Prosthetic heart Valves & 20 & 16.9 \\
\hline Atrial septal defect & 02 & 1.6 \\
\hline Ventricular Septal Defect & 04 & 3.3 \\
\hline
\end{tabular}

\section{Table 5: Sites of Vegetation in IE patients (total $n=118$ )}

\begin{tabular}{|l|l|l|}
\hline Site & N & Percentage(\%) \\
\hline Mitral Valve & 59 & 50 \\
\hline Aortic Valve & 28 & 23.7 \\
\hline Tricuspid Valve & 21 & 17.7 \\
\hline Pulmonary valve & 10 & 8.4 \\
\hline
\end{tabular}

Table 6: Microbiological spectrum in Patients with NVE

\begin{tabular}{|l|l|}
\hline Microbiological Spectra & Number of Isolates N(\%) \\
\hline Streptococcus mitis & $9(36)$ \\
\hline Streptococcus sanguinis & $3(12)$ \\
\hline Streptococcus pyogenes & $3(12)$ \\
\hline Streptococcus pneumoniae & $2(8)$ \\
\hline $\begin{array}{l}\text { Methicillin Resistant } \\
\text { Staphylococcus aureus }\end{array}$ & $3(12)$ \\
\hline $\begin{array}{l}\text { Methicillin susceptible } \\
\text { Staphylococcus aureus (MSSA) }\end{array}$ & $2(8)$ \\
\hline Stenotrophomonas maltophilia & $1(4)$ \\
\hline Brevundimonas diminuta & $1(4)$ \\
\hline Brucella melitensis & $1(4)$ \\
\hline
\end{tabular}

Table 7: Microbiological spectrum in Patients with NVE

\begin{tabular}{|l|l|}
\hline Microbiological Spectra & Number of Isolates N(\%) \\
\hline $\begin{array}{l}\text { Methicillin Resistant Staphylococcus } \\
\text { aureus (MRSA) }\end{array}$ & $4(30.7)$ \\
\hline $\begin{array}{l}\text { Methicillin susceptible } \\
\text { Staphylococcus aureus (MSSA) }\end{array}$ & $4(30.7)$ \\
\hline $\begin{array}{l}\text { Methicillin Resistant Coagulase } \\
\text { negative Staphylococcus (MRCONS) }\end{array}$ & $3(23.0)$ \\
\hline Streptococcus pyogenes & $2(15.3)$ \\
\hline
\end{tabular}

\section{DISCUSSION}

IE is an infection of endothelial surface of heart, which can have devastating and lethal outcomes if not treated aggressively with antibiotics. (2).In Developed countries, IE is seen mostly in elderly patients with a gradual increase in mean age of IE patients(2), however the mean age of IE in our study was 30 years.(table I) which is consistent with the previous studies from developing countries including india.(3)(4). The most common predisposing factor for infective endocarditis was Chronic Rheumatic Heart Disease as consistent with previous studies $(5,6,7,8)$. The Most common clinical feature observed in the study was fever $(67.7 \%)$ as consistent with previous studies(8), followed by embolic episodes, and rarely heart murmur and chest discomfort. NVE was more common(83.05\%) than PVE as consistent with previous studies. $(10,5,11)$. In developing countries like India, Senthil et al. (10) observed PVE in $4.3 \%$ of cases and Mario et al. (5) in 30\% of cases. In case of PVE most common organism isolated were Methicillin Resistant Staphylococcus aureus (MRSA) $(30.7 \%, \mathrm{n}=4)$, Methicillin susceptible Staphylococcus aureus (MSSA) $(30.7 \%, n=4)$, Methicillin Resistant Coagulase negative Staphylococcus (MRCONS) $(23.0, n=3)$, Streptococcus pyogenes $(15.3 \% \mathrm{n}=2)$. It was consistent with the observation of Murdoch et al (12), who noted that most common organism found in patients with prosthetic valves and IVDU were Staph aureus. In case of NVE, most common isolated organisms included Streptococcus $\operatorname{mitis}(36 \% n=9)$, Streptococcus sanguinis $(12 \%, n=3)$, Streptococcus pyogenes $(12 \% \mathrm{n}=3)$, which was consistent with the previous studies in india (13).

\section{CONCLUSION:}

In our retrospective study the mean age of patients was 30 years, most of the patients belonged to age group of 41-50 years with a male predominance(1.4:1). The most common presenting complain of patients was fever(67.7\%), with Native valve endocarditis being more common than Prosthetic valve endocarditis, with mitral valve being commonly affected, with chronic rheumatic heart disease as most common underlying condition. Among Both the Groups(NVE and PVE) culture negative endocarditis was more common than culture positive cases. In NVE culture positive cases the most common organism isolated was streptococcus mitis, where as in PVE most common organism isolated was Methicillin resistant Staphyloccocus aureus.

\section{REFERENCE:}

1. Li JS, Sexton DJ, Mick N, Nettles R, Fowler VG Jr, Ryan T, Bashore T, Corey GR. Proposed modifications to the Duke criteria for the diagnosis of infective endocarditis. Clin Infect Dis. 2000 Apr;30(4):633-8. doi: 10.1086/313753. Epub 2000 Apr 3. PMID 10770721.

2. Kucukates E, Gultekin N, Bagdatli Y. Cases of active infective endocarditis in a university hospital during a 10-year period. J Pak Med Assoc 2013;63:1163-1167. [PubMed] [Google Scholar]

3. Khan NU, Farman MT, Sial JA, Achakzai AS, Saghir T, Ishaq M. Changing trends of infective endocarditis. J Pak Med Assoc 2010;60:24-27. [PubMed] [Google Scholar]

4. Agca FV, Demircan N, Peker T, Ari H, Karaagac K, Ozluk OA, et al. Infective endocarditis: a tertiary referral centre experience from Turkey. Int J Clin Exp Med 2015;8:13962-13968. [PMC free article] [PubMed] [Google Scholar]

5. Nunes MC, Gelape CL, Ferrari TC. Profile of infective endocarditis at a tertiary care center in Brazil during a seven-year period: prognostic factors and in-hospital outcome. Int J Infect Dis 2010;14:e394-398. [PubMed] [Google Scholar]

6. Kothari SS, Ramakrishnan S, Bahl VK. Infective endocarditis--an Indian perspective, Indian Heart J 2005; 57: 289-294. [PubMed] [Google Scholar]

7. Jain SR, Prajapati JS, Phasalkar MA, Roy BH, Jayram AA, Shah SR, Singh T, et al. Clinical spectrum of infective endocarditis in a tertiary care centre in western India: A prospective study. IJCM 2014;5:177-187. [Google Scholar]

8. Tuğcu A, Yildirimtürk O, Baytaroğlu C, Kurtoğlu H, Köse O, Sener M, et al. Clinical spectrum, presentation, and risk factors for mortality in infective endocarditis: a review of 68 cases at a tertiary care center in Turkey. Turk Kardiyol Dern Ars 2009;37:9-18. [PubMed] [Google Scholar]

9. Hosseini SM, Bakhshian R, Moshkani Farahani M, Abdar Esfahani M, Bahrami A, Sate A. An observational study on infective endocarditis: A single center experience. Res Cardiovasc Med 2014;3(4):e18423. [PMC free article] [PubMed] [Google Scholar]

10. Senthilkumar S, Menon T, Subramanian G. Epidemiology of infective endocarditis in Senthilkumar S, Menon T, Subramanian G. Epidemiology of infective endocarditis in
Chennai, South India. Indian J Med Sci 2010;64:187-191. [PubMed] [Google Scholar]

11. Loupa C, Mavroidi N, Boutsikakis I, Paniara O, Deligarou O, Manoli H, et al. Infective
11. endocarditis in Greece: a changing profile. Epidemiological, microbiological and therapeutic data. Clin Microbiol Infect 2004;10:556-561. [PubMed] [Google Scholar]

12. Murdoch DR, Corey GR, Hoen B, Miró JM, Fowler VG, Bayer AS, et al. Clinical presentation, etiology, and outcome of infective endocarditis in the 21 st century. Arch Intern Med 2009;169:463-473. [PMC free article] [PubMed] [Google Scholar]

13. Siddiqui BK, Tariq M, Jadoon A, Alam M, Murtaza G, Abid B, et al. Impact of prior antibiotic use in culture-negative endocarditis: review of 86 cases from southern Pakistan. Int J Infect Dis 2009;13:606-612. [PubMed] [Google Scholar] 